\title{
EL IMPACTO EN EL ORDENAMIENTO JURÍDICO ESPAÑOL DEL INFORME DEL CONSEJO DE ESTADO SOBRE LAS PROPUESTAS DE MODIFICACIÓN DEL RÉGIMEN ELECTORAL GENERAL
}

\author{
MARÍA LUZ MARTÍNEZ ALARCÓN \\ Profesora Titular de Derecho Constitucional \\ Universidad de Castilla La Mancha
}

TRC, núm. 45, 2020, pp. 403-427

ISSN 1139-5583

\begin{abstract}
SUMARIO
I. Introducción. II. La disociación entre nacionalidad y ciudadanía: la utilización de la residencia y del vínculo efectivo como elementos determinantes para decidir sobre la atribución del derecho de sufragio en elecciones locales. III. Modificaciones del ejercicio del derecho al voto desde el exterior. IV. Reformas para incrementar la proporcionalidad en las elecciones al Congreso de los Diputados y ampliar las posibilidades de participación de los electores. V. La circunscripción electoral en las elecciones al Parlamento Europeo. VI. La elección directa de alcaldes. VII. Corrección de defectos de las normas que regulan la confección del censo electoral y las campañas electorales; utilización de nuevas tecnologías. VIII. El impacto del Informe del Consejo de Estado en el régimen electoral general español.
\end{abstract}

\section{INTRODUCCIÓN}

En un Estado democrático, el proceso de constitución del poder constituido debe ser la consecuencia de un acto de mediación del pueblo. En concreto, las competencias de los poderes legislativo y ejecutivo solo se encomiendan por un tiempo; en relación con los mismos, no podemos hablar de una legitimación permanente o ad aeternum, sino periódica y necesitada de renovación constante. Por tanto, la celebración de elecciones periódicas por sufragio es uno de los elementos consustanciales al sistema democrático.

Ahora bien, tanto el sufragio, como los procesos electorales a través de los cuales se expresa, deben generar una representación política adecuada del cuerpo 
electoral. Y ello implica, en primer lugar, que el sufragio debe ajustarse a una serie de características (por eso nuestra Constitución habla de sufragio universal, libre, igual, directo y secreto), y, en segundo lugar, que los elementos del sistema electoral, esto es, los rasgos determinantes del resultado de unas elecciones fundamentalmente circunscripción electoral, fórmula electoral, forma de expresión del voto y barrera o umbral electoral - deben garantizar una traducción de los votos en escaños que refleje de la manera más fidedigna posible el pluralismo político. Solo así se puede «conjurar el riesgo de que quienes resulten perdedores en el juego electoral dejen por ello de acatar el resultado y no acepten seguir jugando las mismas reglas» ${ }^{1}$.

El día 30 de junio de 2010, la Comisión Constitucional del Congreso aprobó el Informe elaborado por la Subcomisión, creada en su seno, de estudio de posibles modificaciones del régimen electoral general. Este Informe planteaba cambios inspirados en propuestas presentadas por los Grupos Parlamentarios, pero también en otras procedentes de Informes provenientes de la Junta Electoral Central y del Consejo de Estado y de trabajos especializados en la materia. Sus resultados se concretaron, finalmente, con la aprobación de la LO 2/2011, de 28 de enero, por la que se modifica la LO 5/1985, de 19 de junio, del Régimen Electoral General, la cual alude, en su Preámbulo, a la influencia del Informe del Consejo de Estado sobre las propuestas de modificación del régimen electoral general a propósito de alguno de los cambios introducidos, y de la Ley Orgánica 3/2011, de 28 de enero, por la que se modifica la LO 5/1985, de 19 de junio, del Régimen Electoral General (que no resulta de interés para el objeto de este trabajo) ${ }^{2}$.

Como sabemos, el Consejo de Estado fue interpelado el 27 de junio de 2008 para realizar un estudio sobre las principales propuestas, políticas y doctrinales, de reforma y mejora, en términos de democracia, del régimen electoral general. El resultado fue el Informe sobre las propuestas de modificación del régimen electoral general de 24 de febrero de 2009, caracterizado, en nuestra opinión, por dos rasgos fundamentales: por su indiscutible calidad técnica, que lo ha convertido en un texto de referencia obligada para todos aquellos que analizan en España la reforma del sistema electoral general, y por una laudable cautela en el tratamiento del tema ${ }^{3}$.

1 CONSEJO DE ESTADO. Informe sobre las propuestas de modificación del régimen electoral general, de 24 de febrero de 2009, p. 11. Disponible en El Informe del Consejo de Estado sobre la reforma electoral. Texto del Informe y debates académicos, Consejo de Estado-CEPC, Madrid, 2009.

2 Ambas publicadas en el BOE $\mathrm{n}^{\circ} 25$, de 29 de enero de 2011. Sobre la diversa posición de las diferentes fuerzas políticas en el momento de comenzar los trabajos de la Subcomisión Fernández-Miranda CamPOAMOR, A., «Sobre la reforma electoral», El Informe del Consejo de Estado sobre la reforma electoral. Texto del informe y debates académicos, Consejo de Estado-CEPC, Madrid, 2009, p. 675.

3 Parece considerar que el régimen electoral español ha resultado razonablemente exitoso y que resulta preferible ir realizando las adaptaciones que vaya precisando. Se renuncia así a una modificación radical del mismo. Al respecto Chueca Rodríguez, R., «Cambios, reformas y adaptaciones», La reforma de la Ley 
Los trabajos del Consejo de Estado se ciñeron al mandato del Gobierno y, por ello, solo analizaron propuestas que no precisaban reforma constitucional. El órgano consultivo se pronunció sobre el derecho de sufragio de los extranjeros residentes en España y de los españoles residentes en el extranjero; las propuestas planteadas para incrementar la proporcionalidad en las elecciones al Congreso de los Diputados y la ampliación de las opciones ofrecidas a los electores (listas electorales); la creación de circunscripciones de ámbito subestatal para las elecciones al Parlamento Europeo; la elección directa de los alcaldes; y la corrección de algunos defectos percibidos en las normas que regulaban el censo electoral y las campañas electorales a fin de prevenir posibles fraudes o situaciones de desigualdad entre los partidos participantes, así como sobre la utilización de las nuevas tecnologías. Nuestra intención es retomar de forma sinóptica los contenidos de aquel trabajo a fin de comprobar cuál fue su verdadero impacto en la reforma del régimen electoral general del año 2011.

\section{LA DISOCIACIÓN ENTRE NACIONALIDAD Y CIUDADANÍA: LA UTILIZACIÓN DE LA RESIDENCIA Y DEL VÍNCULO EFECTIVO COMO ELEMENTOS DETERMINANTES PARA DECIDIR SOBRE LA ATRIBUCIÓN DEL DERECHO DE SUFRAGIO EN ELECCIONES LOCALES}

El Informe del Consejo se mostró favorable a la idea de desvincular el derecho de sufragio en las elecciones locales celebradas en España del estatuto de la nacionalidad y de vincularlo a la idea de residencia y vínculo efectivo teniendo en cuenta la diversa naturaleza que atribuía a los comicios locales (corporativa) y al

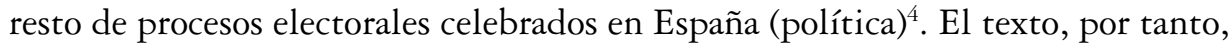
constituye una más de las múltiples expresiones que, desde hace algún tiempo en la doctrina, desliga el estatuto jurídico de la nacionalidad, entendida como el vínculo jurídico de pertenencia de los individuos a una comunidad social organizada como comunidad jurídico-política estatal en la que todos asumen las mismas obligaciones y disfrutan de los mismos derechos, del estatuto jurídico de la ciudadanía, entendida como aquella cualidad del individuo que le permite participar en la cosa pública a través, entre otros, del derecho de sufragio (activo y/o

\footnotetext{
Orgánica del Régimen Electoral General, presentación y coordinación de E. PajAREs Montolío, Foro «Democracia y representación», CEPC, Madrid, 2011, pp. 22-23.

4 El vínculo entre nacionalidad y ciudanía sirvió inicialmente para garantizar el ejercicio del sufragio a todos los nacionales con independencia de cualquier otra condición (patrimonio, capacidad). En este sentido Santolaya Machetti, P. y Díaz Crego, M., El sufragio de los extranjeros. Un estudio de derecho comparado, Cuadernos y Debates, $\mathrm{n}^{\circ} 183$, CEPC, Madrid, 2008, p. 11 y ss. En la actualidad, la cuasi identidad entre nacionalidad y ciudadanía excluye del sufragio a unas personas de origen extranjero que se asientan como residentes en el territorio de acogida con pretensión de estabilidad y arraigo en el marco de unas nuevas sociedades transformadas.
} 
pasivo en alguno o algunos de los procesos electorales celebrados en el Estado, según el autor de que se trate ${ }^{5}$ ). En concreto, este órgano consultivo defendió, por un lado, la atribución del derecho de sufragio activo - y también pasivo, aunque con menor contundencia ${ }^{6}$ - a los extranjeros (o personas de origen inmigrante ${ }^{7}$ ) residentes en España en las elecciones locales (su tesis afectó únicamente a personas de origen inmigrante residentes legales. La ilegalidad de la residencia y el consiguiente deber de abandonar el territorio nacional que imponía la legislación de extranjería justificaría, según el Consejo de Estado, una política de retorno más que de representación e integración); y, por otro, la supresión del derecho de sufragio activo de los españoles residentes en el exterior, también para las elecciones locales celebradas en España.

En primer lugar, y en relación con las personas de origen inmigrante regulares en España, sus propuestas fueron en la línea de ampliar a niveles de máximos - cuando resultara posible sin reforma constitucional- sus posibilidades de ejercicio del sufragio activo en las elecciones locales. En su opinión, dos razones

5 Entre otros Goig Martínez, J.M., Multiculturalidad, integración y derechos de los inmigrantes en España, Dykinson, Madrid, 2015; ARCE JimÉnez, C., Los derechos políticos de los residentes extranjeros: la ciudadanía inclusiva, Defensor del Pueblo andaluz, 2012; Ortega Jiménez, A., El derecho de voto de los ciudadanos extracomunitarios en las próximas elecciones españolas de 2011, Fundación Alternativas, 2011; LuCAs MARTín, J. de y otros, Los derechos de participación como elemento de integración de los inmigrantes, Fundación BBVA, Madrid, 2008; LuCAS Martín, J. de, «Ciudadanía, extranjería y derecho», en AA.VV., Constitución y derechos fundamentales, Ministerio de la Presidencia, CEPC, Madrid, 2004; o «Las condiciones de un pacto social sobre la inmigración», Inmigración y derechos. Segundas jornadas sobre derechos humanos y libertades fundamentales, coord. por M. Calvo García y N. Fernández Sarasola, 2001; AlberTi, E., «El derecho de voto de los extranjeros: una condición imprescindible para la integración», Informe anual 2007. Sobre el racismo en el Estado español, Icaria Editorial, Barcelona, 2007; IBÁÑEz Macías, A., El derecho constitucional a participar y la participación ciudadana local, Grupo Difusión, Madrid, 2007, p. 125 y ss.; Revenga SÁnCHez, M., «El reto de la normalización del inmigrante», en P. SAntolaya - M. Revenga SÁnChez, Nacionalidad, extranjería y derecho de sufragio, Foro Inmigración y Ciudadanía, 13, CEPC, Madrid, 2006; Presno Linera, M. Á., «El sufragio de los extranjeros residentes en las elecciones generales como exigencia de una ciudadanía democrática», $R E D C, \mathrm{n}^{\circ} 27,2016$; La reforma del derecho de voto en España, Tribunal Judicial de la Federación, 2011; «El voto de los extranjeros en España y el voto de los españoles residentes en el extranjero. A propósito del Informe del Consejo de Estado sobre las propuestas de modificación del Régimen Electoral General», REDC, nº 87, 2009; «La participación política como forma de integración», en M.Á. PRESNO LINERA, Extranjería e inmigración: aspectos jurídicos y socioeconómicos, Tirant lo Blanch, Valencia, 2004; o El derecho de voto, Tecnos, Madrid, 2003; MASSÓ GARROTE, M. Fco., Los derechos políticos de los extranjeros en el Estados nacional. Los derechos de participación politica y el derecho de acceso a funciones públicas, Colex, Madrid, 1997; Rodríguez-Drincourt Álvarez, J., Los derechos políticos de los extranjeros, Civitas, Madrid, 1997.

6 Los argumentos que va a ofrecer para ampliar las posibilidades del sufragio activo los entiende aplicables al sufragio pasivo, aunque les reconoce mayor peso en el caso del sufragio activo que pasivo (por tanto, no excluyó que la regulación pudiera diferir en función del tipo de sufragio de que se tratara).

7 Utilizaremos la expresión «persona de origen inmigrante» y solo de manera excepcional, por cuestiones estilísticas, las expresiones «inmigrante» y «extranjero», siguiendo a VinTILA, D. y MORALES, L., en «La representación política de las personas de origen inmigrante en España e Italia», Papers, 103/4, 2018, pp. 521-550. Nos parece que la misma pone el acento en la condición de «persona» y menos en la de «inmigrante». Además, nos parece preferible utilizar la noción de «persona de origen inmigrante» a la utilización del término «extranjero», que ha adquirido una connotación claramente peyorativa (identificándolo con el «extraño» cuando no con el «enemigo»). 
fundamentales avalaban esta posición: la necesidad de asegurar su representación en el nivel local, y la de favorecer su integración en el municipio. Nosotros compartimos tanto su posición como las razones que la avalan.

En materia de representación, denunció el sinsentido democrático de excluir del sufragio a un elevado porcentaje de la población que resultaba destinataria de las decisiones adoptadas por unas instituciones representativas en las que, sin embargo, no encontraba representación. En su opinión, debía ser la residencia en el municipio, no la nacionalidad, el criterio decisivo para ser titular del derecho de sufragio en las elecciones locales (recordaba que el artículo 140 CE señala que los concejales serán elegidos por los «vecinos» del municipio - no hace referencia a nacionales- y los alcaldes por los concejales o los «vecinos»). Por otra parte, resulta evidente que una inclusión e integración de los individuos en las comunidades en las que desarrollan su proyecto vital exige, desde un punto de vista jurídico, el reconocimiento previo de derechos, incluidos aquellos que garantizan su participación en los asuntos públicos (entre otros, el sufragio). No olvidemos que los derechos de participación política, al permitir constituirse en grupo social con relevancia pública, funcionan como garantía fundamental de los derechos de autonomía y sociales. Sensu contrario, el reconocimiento separado de tipos de derechos (el status libertatis o esfera de autonomía del individuo frente al Estado y el status civitatis o derecho a participar en la formación de la voluntad estatal) puede conducirnos a la ineficacia de los derechos que el ordenamiento jurídico español atribuye formalmente a los no nacionales.

Tras pronunciarse sobre las razones que avalaban la atribución del sufragio a los extranjeros residentes en España en comicios locales, procedió, posteriormente, a plantear una serie reformas legales, o a ofrecer determinadas pautas hermenéuticas, con el objeto de maximizar las posibilidades de participación por parte de las personas de origen inmigrante residentes en España en las elecciones locales.

Primero, defendió la utilización de la ley para concretar dicha participación (es evidente la diferencia existente en términos de complejidad entre decidir unilateralmente al respecto o estar obligado a alcanzar un acuerdo con otras voluntades estatales — la adopción de tratados requiere de la voluntad política de ambas Partes de forma que el derecho al voto quedará condicionado, no tanto por la situación de vecindad, sino por la procedencia del extranjero-, además de que la vía internacional se puede convertir en una herramienta al servicio de los intereses de la política exterior española relegando a un segundo plano el tema de la participación ciudadana ${ }^{8}$ ). Ello exigiría la reforma de los arts. 176 y 177 LOREG

8 Arce Jiménez, C., «Análisis de los tratados internacionales para el reconocimiento del derecho de sufragio local a personas extranjeras residentes en España que no ostentan la ciudadanía europea», Revista de estudios de la Administración Local y Autonómica, n 11, abril-septiembre 2019. Subraya como significativo que seis de las quince principales nacionalidades de residentes extranjeros extracomunitarios en España no tengan reconocido el sufragio local por no existir el correspondiente tratado. 
que asumían entonces - lo siguen haciendo- que esta materia debe concretarse en un tratado internacional ${ }^{9}$. En segundo lugar, afirmó que no resultaba preciso, para extender el derecho de sufragio en estos casos, exigir que los países de origen de estos extranjeros se caracterizaran por un sistema de fair and free elections (en realidad, los arts. 176 y 177 LOREG no imponen que los tratados internacionales se concluyan con países que garanticen fair and free elections). En tercer lugar, le pareció especialmente importante que se realizara una interpretación extensiva del principio de reciprocidad, muy criticado al haber sido considerado el mayor obstáculo para conseguir la incorporación de los extranjeros a la sociedad como miembros de pleno derecho ${ }^{10}$. El Consejo, entre las posibilidades de entender la reciprocidad, bien como identidad o como igualdad muy rigurosa en el tratamiento o regulación que ambos Estados daban al asunto, bien como una mera semejanza o similitud, apostó por esto último señalando que bastaría con prever en la ley la concurrencia de unas reglas mínimas de reciprocidad para poder acceder, por parte del extranjero residente en España, al reconocimiento del derecho de sufragio en las elecciones locales (el tenor literal de los arts. 176 y 177 LOREG permite dicha interpretación). Para el Consejo, por tanto, sería posible que los derechos se reconocieran con menores restricciones a las personas de origen inmigrante residentes en España que a los españoles en el extranjero.

Finalmente, apuntó que la exigencia de un periodo previo de residencia para poder ejercer el derecho de sufragio por las personas de origen inmigrante residentes en España en los comicios electorales resultaba consistente con la exigencia de una vinculación efectiva con un municipio determinado. Propuso, al respecto, valorar un periodo de residencia de aproximadamente cinco años, si bien con la posibilidad de reconocer diferencias entre grupos de extranjeros en función de su particular vinculación con España. Nos interesa ahora destacar que aunque, según el Consejo de Estado, la situación de residencia del inmigrante en España permite hablar de la existencia de un vínculo entre el extranjero residente

9 Sobre los acuerdos concluidos por el Estado español con otros países para permitir el ejercicio del derecho de sufragio por parte de las personas de origen inmigrante en las elecciones locales en nuestro país, ibídem, pp. 139-155; y CARrasco Durán, M., «El derecho de voto de los extranjeros en las elecciones municipales. Nuevas realidades», Fundación Democracia y Gobierno Local, QDL, 22 de febrero de 2010; pp. $150-152$.

10 Entre otros, ORTega Jiménez, A., El derecho de voto de los ciudadanos extracomunitarios en las próximas elecciones municipales españolas de..., cit.; Chueca Sancho, Á. G. y Aguelo Navarro, P., «El derecho de voto de los extranjeros en España en perspectiva europea», Documentos CIDOB. Migraciones, n 19, 2009, p. 36; IBÁÑEZ Macías, A., El derecho de sufragio de los extranjeros, Dykinson, Madrid, 2009, p. 82; VACAs FernÁNDEZ, F., «El principio de reciprocidad como condición del reconocimiento del derecho al sufragio de extranjeros en las elecciones municipales en España y sus implicaciones desde el Derecho Internacional», Revista de Derecho Migratorio y Extranjería, no 20, 2009, p. 92; Aja FernÁndez, E. y Moya Malapeira, D., «El derecho de sufragio de los extranjeros residentes», La inmigración en la encrucijada, coord. por E. Aja Fernández, J. Arango Vila-Belda y J. Oliver I Alonso, 2008, p. 73; o García Soriano, M.V., «Sobre la viabilidad de la participación política de los extranjeros en las elecciones municipales», Cuadernos Constitucionales de la Cátedra Fadrique Furió Ceriol, no 60-61, 2007, p. 264. 
y el país de residencia, no permitiría hablar del vínculo «efectivo» requerido para poder disfrutar del sufragio en las elecciones locales. Para poder disfrutar del mismo sería preciso justificar una residencia legal en el territorio español durante un determinado número de años.

En segundo lugar, también utilizó el criterio de la residencia para concluir que procedía replantearse la titularidad del derecho de sufragio activo de los españoles residentes en el extranjero en las elecciones locales celebradas en España ${ }^{11}$. A su juicio, una reforma para excluir del voto en elecciones locales a los españoles residentes en el extranjero no contravendría la Constitución (su art. 68.5 se refiere a las elecciones al Congreso, y, además, el art. 140 del mismo texto prevé la elección de los concejales por los «vecinos» del municipio) ${ }^{12}$. Recordó, en apoyo a su tesis, que era habitual que los Estados que permitían el ejercicio del sufragio por parte de sus nacionales que vivían en el exterior sometieran el mismo a algún tipo de requisito adicional más allá de la nacionalidad y la edad con el fin de asegurar la conexión del elector con la vida política del país, y que, además, la regla general era no reconocer este derecho en todo tipo de comicios. Además, señaló que la Comisión de Venecia no consideraba una exigencia democrática la participación de los nacionales residentes en el extranjero en los comicios municipales o regionales.

Llegados a este punto, es preciso subrayar que el Consejo entendió que la residencia del español en otro país podía implicar la pérdida, de forma inmediata, de su derecho al voto en las elecciones locales celebradas en España (como consecuencia de la pérdida de un vínculo efectivo con el municipio abandonado).

11 Sobre el contexto social existente en el momento de la elaboración del Informe, con un número considerable de españoles residentes en el extranjero que podían ejercer el derecho de voto sin haber residido nunca en España o que probablemente no tenían intención de volver a hacerlo al haberse instalado de forma bastante definitiva en otro país, y la aprobación de la Ley 52/2007, de 26 de diciembre — conocida como Ley de Memoria Histórica - que iba a aumentar dicho número al facilitar la adquisición de la nacionalidad en favor de quienes padecieron persecución o violencia durante la guerra civil y la dictadura; CHUECA RoDRíGUEZ, R., "Cambios, reformas y adaptaciones», La reforma de la Ley Orgánica del Régimen Electoral..., cit., pp. 37-38. Sigue constituyendo una obra de referencia, si bien ya un poco lejana, Arnaldo Alcubilla, E., El derecho de sufragio de los emigrantes en el ordenamiento español, CEC, Madrid, 1995.

12 Sí que podía plantear problemas, sin embargo, su exclusión de procesos electorales de ámbito nacional. La distinta naturaleza, corporativa en el caso de las elecciones locales, y política en el caso de las elecciones nacionales, justificaba un tratamiento distinto del voto de los españoles residentes en el extranjero. Éste es, por cierto, uno de los puntos oscuros del Informe del Consejo de Estado que, en nuestra opinión, no logra explicar con la claridad que caracteriza al conjunto del texto, la diferencia existente entre comicios políticos y comicios corporativos (las razones que permiten diferenciar un tipo de comicios de otros en España no son coincidentes entre los que se han pronunciado al respecto. Incluso existe un sector doctrinal que considera que no hay razón alguna para diferenciar). Ahora bien, del mismo parece desprenderse que la diferencia de naturaleza entre los mismos radica en el hecho de que unos — los nacionales - dan lugar a órganos de representación que adoptan decisiones que pueden afectar a la vida de los emigrantes (son así sus destinatarios), mientras que otros — los municipales_ - dan lugar a órganos de representación con competencias mucho más limitadas, que no tienen incidencia en la vida de los emigrantes. Los españoles residentes en el exterior pueden ser destinatarios — disfrutar de o sufrir los efectos- de decisiones adoptadas por los órganos de representación nacionales, pero no de las aprobadas por los órganos de representación locales. 
Ahora bien, si, según el Consejo, la residencia no puede generar el vínculo efectivo necesario para poder disfrutar del sufragio en elecciones locales por parte de personas de origen inmigrante en España, sino que resulta preciso, además, acreditar un determinado periodo de residencia que sería prueba de su arraigo, ¿no hubiera resultado más congruente concluir que la adquisición de la residencia por parte de un español en el exterior no conlleva, de forma automática, la pérdida del vínculo efectivo, y haber exigido, para ello, un determinado periodo de residencia en el exterior? De hecho, el Consejo, consciente de la polémica que provocaría la supresión del derecho de voto de los españoles residentes en el extranjero en las elecciones locales, concluyó aconsejando otro tipo de soluciones más moderadas y alternativas hasta tanto en cuanto no se llegara a alcanzar la medida deseable, consistente en la supresión del voto de los españoles en el extranjero desde el mismo momento en que adquirieran la residencia del país de acogida. Propuso, en primer lugar, exigir al español residente en el exterior una vinculación efectiva con el municipio español de inscripción que se plasmaría en que no hubiera transcurrido un determinado periodo de tiempo desde que lo abandonó (solución presente en el Derecho Comparado y que excluiría de raíz del derecho de sufragio municipal a los españoles nacionales fuera del Estado español que nunca hubieran residido en el mismo). La razón: a medida que aumenta el periodo de residencia habitual del residente ausente en el país de acogida, disminuye progresivamente el vínculo de unión con el municipio en el que vivía en España antes de establecerse en el exterior. Y planteó, en segundo lugar, la pérdida del derecho de voto en las elecciones locales españolas para aquellos españoles que pudieran votar en el municipio extranjero de residencia (sensu contrario, la negación del mismo derecho en el Estado acogida implicaría su reconocimiento en España ${ }^{13}$.

\section{MODIFICACIONES DEL EJERCICIO DEL DERECHO AL VOTO DESDE EL EXTERIOR}

De naturaleza más técnica fueron las propuestas analizadas por el Consejo de Estado sobre el ejercicio del derecho al voto desde el exterior. El órgano centró su reflexión en la circunscripción utilizada para el cómputo de los sufragios emitidos por los nacionales residentes en el extranjero y en el modo de expresión material del voto. También realizó alguna observación, de orden menor, en relación con la campaña electoral.

Tras reconocer que el mecanismo utilizado de computar los votos en el exterior mediante la ficción de adscribir formalmente a los ciudadanos ausentes a

13 En la doctrina, por poner un ejemplo, PRESNO LINERA censura la situación que permite ejercer el derecho de voto, con independencia del tipo de comicios de que se trate, a los nacionales que nunca han vivido en el territorio de su Estado o que llevan un número mínimo de años fuera de él (habla de cinco o más años); Presno Linera, M.Á., La reforma del derecho de voto en..., cit., pp. 106-113. 
algún municipio español no garantiza la conexión entre los emigrantes y los representantes elegidos por la circunscripción correspondiente, ni permite a los primeros hacer valer sus intereses específicos al diluirse sus sufragios en diferentes circunscripciones territoriales, rechazó de plano, consideramos que de forma acertada, las propuestas que defendían la creación de una circunscripción especial exterior con la consiguiente reserva de la elección de un determinado número de miembros en el órgano parlamentario a favor de los españoles residentes en el extranjero (recordemos que la circunscripción electoral en España es la provincia por prescripción constitucional).

Sin embargo, realizó el esfuerzo de analizar la viabilidad de plantear alguna vía alternativa que pudiera mitigar la falta de conexión entre emigrantes y representantes. En concreto, reflexionó sobre la posibilidad —en términos constitucionales- y conveniencia de computar todos los sufragios emitidos en el extranjero en las elecciones generales en una única circunscripción provincial, lo que sin duda podría repercutir en sentido positivo en la presencia parlamentaria de las preocupaciones concretas de los españoles residentes en el extranjero. No obstante ello, acabó rechazando la medida debido a sus efectos adversos, consistentes en que la concurrencia de los votos procedentes del extranjero y de los votos de los residentes en el municipio de la provincia correspondiente produciría una distorsión de la relación entre representantes y sus electores por cuanto estos procederían de dos grupos dispares, sobre todo si la provincia de referencia representaba un territorio poco poblado. En tal caso, sus residentes podrían sentirse agraviados si los candidatos primaran los mensajes dirigidos a los ciudadanos ausentes por recaer en ellos un mayor peso —o un peso muy importante- en la elección. Si, por el contrario, la provincia de referencia fuera una muy poblada, la medida no produciría el impacto buscado, es decir, no sería idónea para conseguir el resultado pretendido, ya que probablemente se produciría una difuminación de los intereses específicos de quienes viven fuera de España sin que la adopción de tal sistema representara una mejora efectiva para la defensa de sus intereses. Ninguna de las opciones convencieron al Consejo, que no planteó así ninguna propuesta de modificación en relación con esta materia en su Informe.

Con relación a la forma de ejercicio del derecho al voto por parte de los españoles residentes en el extranjero, se centró en la inscripción censal y el procedimiento de votación.

Comenzó valorando positivamente - como la doctrina - la reforma de la LOREG por LO 3/1995, de 23 de marzo $^{14}$, del Censo de los Españoles Residente Ausentes (CERA), que, entre otras cosas, introdujo la inscripción censal automática o de oficio sustituyendo la inscripción censal a instancia del interesado (salvo para el caso de las elecciones locales). Únicamente aconsejó actuar para poner remedio a la preocupante insuficiencia de medios materiales y personales de los

14 BOE núm. 71, de 24 de marzo de 1995. 
que disponían las oficinas consulares para la tramitación y depuración de los correspondientes Registros de Matrícula, de cuya fiabilidad dependía el CERA. Además, tras rechazar de plano un voto por procuración (contrario a los principios de personalidad y secreto del sufragio), se mostró sumamente cauteloso con la posibilidad de introducir el voto en urna en el extranjero. Para el Consejo, las dificultades técnicas que planteaba la previsión de un voto en urna para estos casos (elevado coste de instauración del sistema; o el hecho de que alguna de las garantías electorales de la votación en persona no puedan reproducirse en el exterior sin unos ajustes difíciles de ejecutar, por ejemplo, en relación con la Administración electoral), desaconsejaban su implantación. Pero, de decidirla, no debía suponer la supresión del sufragio por correo, toda vez que la imposición al elector de la carga de desplazarse hasta el lugar de votación contradiría el mandato constitucional de facilitar el ejercicio del sufragio en el extranjero, sobre todo teniendo en cuenta que, en muchos casos, un porcentaje elevado de los ciudadanos inscritos en el CERA no vive en las ciudades donde radican las Oficinas Consulares. Eso sí, planteó una serie de modificaciones para corregir las disfunciones del voto por correo en el exterior.

Finalmente, compartió el parecer favorable a que se regulasen expresamente los medios específicos de la campaña electoral en el exterior al objeto de garantizar la posición de igualdad entre ausentes y residentes en España a la hora de recibir la información electoral.

\section{REFORMAS PARA INCREMENTAR LA PROPORCIONALIDAD EN LAS ELECCIONES AL CONGRESO DE LOS DIPUTADOS Y AMPLIAR LAS POSIBILIDADES DE PARTICIPACIÓN DE LOS ELECTORES}

La crítica más frecuente al sistema electoral del Congreso de los Diputados ha sido que su diseño provoca una vulneración del principio constitucional de igualdad de sufragio en dos de sus elementos esenciales: la distribución de escaños entre circunscripciones y la atribución de escaños a las candidaturas. Es decir, se discute la diferencia en el valor del sufragio en función de la circunscripción en la que se deposite el voto o la candidatura a cuyo favor se emita.

A proposito de la distribución de escaños entre circunscripciones, la denuncia es que las provincias - las circunscripciones electorales en España- más pobladas se encuentran infrarrepresentadas en número de diputados frente a las menos pobladas ${ }^{15}$. A proposito de la atribución de escaños a las candidaturas, la

15 Sobre la relación entre tamaño de la circunscripción y proporcionalidad del sistema, entre muchos otros, Nohlen, D., Sistemas electorales y partidos políticos, $2^{\text {a }}$ ed., FCE, México, 1998; SAnChÉz Navarro, Á.J., Constitución, igualdad y proporcionalidad electoral, CEPC, Madrid 1998; Fernández SEgado, F., «La 
queja siempre ha sido que las elecciones al Congreso no son suficientemente proporcionales, ya que el sistema beneficia a los partidos más votados, por cuanto obtienen un número de escaños superior al que les correspondería en proporción a los sufragios recibidos, mientras que los menos votados pueden verse penalizados en función del grado de dispersión de los sufragios logrados (además del menor número de votos). El Consejo habló de «severa desproporción» de los partidos minoritarios con vocación nacional y base electoral dispersa. El sistema primaría así la concentración del voto y penalizaría su dispersión en aras a garantizar la formación de mayorías estables de gobierno. También constató que la sobrerrepresentación de los partidos cuyo respaldo electoral se circunscribía a un ámbito territorial limitado era reducida y que su representación electoral obedecía, más bien, al respaldo popular que recibían que a la peculiar caracterización del régimen electoral. En todo caso, recordó que la existencia de algún grado de desproporción no resulta extraña en las elecciones a cámaras bajas si atendemos al Derecho comparado; solo resultarían inadmisibles desde el prisma constitucional si, siguiendo doctrina del Tribunal Constitucional ${ }^{16}$, condujeran a diferencias de representación en las que se observara una desproporción manifiesta (de entidad) y arbitraria (no justificada).

Buena parte de la culpa se atribuye, en los dos casos, a la reducida magnitud de muchas de nuestras circunscripciones (que no se puede sin solucionar sin reforma constitucional). Sin embargo, sí se pueden introducir algunas modificaciones en la LOREG para aumentar la proporcionalidad en la atribución de escaños a las circunscripciones - aumento del número de diputados de trescientos cincuenta a cuatrocientos y reducción de la representación mínima inicial de dos diputados a un diputado por provincia ${ }^{17}$ — y para mejorar la relación existente entre los porcentajes de sufragios y escaños conseguidos —igualmente, aumento del número de diputados de trescientos cincuenta a cuatrocientos diputados y

correlación entre el tamaño de las circunscripciones y las distorsiones de la proporcionalidad en la elección del Congreso», REP, n 79, 1993; RAE, D. W., Leyes electorales y sistema de partidos, CITEP, Madrid 1977.

$16 \mathrm{La}$ proporcionalidad es compatible con criterios que impliquen que el resultado no derive en una excesiva fragmentación; GARAVA DE CARA, J.C., «La reforma de la LOREG: expectativas y alcance», $L a$ reforma de la Ley Orgánica del Régimen Electoral General, presentación y coordinación de E. PAJARES MoNTOLÍO, Foro «Democracia y representación», CEPC, Madrid, 2011, p. 89. SANTOLAYA MACHETTI, P. ya señaló en su día que, en el sistema electoral para las elecciones al Congreso, la proporcionalidad aparecía corregida por elementos destinados a evitar un fraccionamiento de la Cámara, en «Significado y alcance de la Ley Orgánica de Régimen Electoral General», REP, nº 53, 1986, p. 59.

17 El aumento del número de diputados hasta el tope permitido por la Constitución (cuatrocientos) elevaría el número de escaños a repartir entre circunscripciones en función de sus habitantes y compensaría la infrarrepresentación de las provincias más pobladas. La reducción de la representación mínima inicial a un diputado por provincia recortaría las desigualdades representativas entre las circunscripciones pequeñas — las beneficiadas por dicha representación mínima inicial- y las más habitadas (pues serían más los escaños a repartir en proporción a la población). Es verdad que, a su través, se harían más patente, en las circunscripciones pobladas, las correcciones del principio de proporcionalidad de la regla D'Hondt, que benefician a los partidos más votados. Es decir, mejoraría la igualdad de voto pero se acentuarían los efectos mayoritarios del sistema electoral. Con todo, la proporcionalidad global del sistema se incrementaría. 
reducción de la representación mínima inicial de dos diputados a un diputado por provincia, y, además, sustitución de la fórmula electoral D'Hondt por otra de efectos más proporcionales como la fórmula Hare-. Asimismo, el Consejo afirmó que también resultaría posible que los restos sobrantes a nivel provincial, en cuanto votos que no han servido a las respectivas candidaturas para obtener representación, se utilizaran —en cómputo global— para la atribución de escaños adicionales a aquellos partidos que, por las características del sistema electoral español, tuvieran los restos mayores (las objeciones de naturaleza constitucional que se suelen oponer a esta medida se pueden superar ya que la circunscripción electoral continúa siendo la provincia y solo se utilizan los votos sobrantes tras el escrutinio provincial). Esta propuesta, naturalmente, tendría por objeto garantizar una mayor proporcionalidad entre votos obtenidos y escaños asignados para las formaciones políticas minoritarias de implantación nacional y con su voto disperso por el territorio nacional. La fragmentación así sería naturalmente mayor, pero no excesiva según el órgano consultivo.

Finalmente, el Consejo de Estado analizó las posibilidades de cambio de la barrera o umbral electoral (entonces y actualmente el $3 \%$ de los votos válidos emitidos en la circunscripción electoral según el art. 163 LOREG), pero no consideró necesaria su reforma por resultar muy poco operativa en la práctica del régimen electoral español. También concluyó que la sustitución del umbral del $3 \%$ en el nivel provincial por una barrera electoral a nivel nacional, con el objeto de reducir la importancia de los partidos con vocación fundamentalmente territorial que, sin embargo, condicionan de forma decisiva la política nacional, resulta inviable desde el prisma constitucional por su incompatibilidad con la consideración de la provincia como circunscripción electoral.

Pero, además, en la misma sección relativa a las elecciones al Congreso, el Consejo se planteó las posibilidades de cambio de las listas electorales, como sabemos, cerradas y bloqueadas (art. 169.2 LOREG). Al respecto, se mostró muy cauteloso, si bien reconoció que la tendencia en el derecho comparado era la de prever algún grado de personalización del voto de los electores en los sistemas proporcionales. Para el órgano consultivo, la falta de acuerdo sobre el grado de pluralismo interno de los partidos, el carácter programático de las elecciones generales y el escaso número de votantes que presumiblemente confeccionarían su propia lista, unidas a la mayor complejidad que la apertura y desbloqueo de las listas supondría a la hora del escrutinio — por más que esta última circunstancia fuese superable a corto plazo con la aplicación de las nuevas tecnologías-, explicarían la dificultad de avanzar hacia una configuración del proceso electoral en la que los votantes dispusieran de unas más amplias facultades de elección entre los candidatos. Con todo, vería positiva alguna reforma al respecto con el objeto de conseguir que los electores se sintieran más partícipes del proceso electoral y se implicaran más en el mismo. Así, no descartó el desbloqueo de las listas a través del voto preferencial utilizado en la mayor parte de los países europeos para las elecciones legislativas; y apuntó que dicha innovación podría ensayarse primero 
en otros niveles representativos —europeo, autonómicos- ${ }^{18}$, antes de plantear su extensión a las elecciones al Congreso. Por el contrario, no se mostró partidario de reformas radicales como la apertura total de las listas (modelo excepcional en Derecho comparado).

\section{LA CIRCUNSCRIPCIÓN ELECTORAL EN LAS ELECCIONES AL PARLAMENTO EUROPEO}

La determinación de la circunscripción electoral para las elecciones al Parlamento Europeo es fundamentalmente una opción política que corresponde decidir de forma particular a cada Estado miembro (con el límite de que no se desvirtúe globalmente el carácter proporcional del modo de elección). En España, donde, como la mayoría de los Estados miembros, utilizamos una circunscripción nacional única (art. 214 LOREG) y la atribución de escaños se realiza según la formula D'Hondt, sin fijar barrera electoral alguna (art. 216 LOREG), las propuestas de reforma de la circunscripción electoral aplicable a las elecciones al Parlamento Europeo proceden, sobre todo, de partidos de ámbito autonómico. Con carácter general, van en la línea de sustituir o de complementar la circunscripción nacional única con circunscripciones territoriales que tomarían como base el territorio de la Comunidad Autónoma. Estas propuestas tienen encaje constitucional pero el Consejo las rechazó tras valorar sus ventajas e inconvenientes en términos de representatividad, proporcionalidad y relación entre votantes y elegidos.

Comenzó señalando que la opción de una circunscripción electoral de mayor o menor tamaño genera una incidencia que opera en direcciones opuestas. Si el tamaño de la circunscripción es pequeño hay menos proporcionalidad, mayor relación directa entre votante y elegido (aunque si el número a elegir es menor se

18 En la doctrina, las posiciones mayoritarias apuntan a alguna modificación en la configuración actual de nuestras listas electorales, si bien existen diferencias sustanciales en función del alcance de la modificación que plantean (en su mayoría abogan por fórmulas de desbloqueo). Entre los autores que defienden listas desbloqueadas FERNÁNDEZ EsQUER, C., «Las listas desbloqueadas en España: ¿regeneración democrática o espejismo institucionalista?», Apuntes Electorales, n 61, 2019, pp. 135-169; CARrasco Durán, M., «Listas electorales: ¿bloqueadas o desbloqueadas? ¿cerradas o abiertas?, Revista General de Derecho Constitucional, $\mathrm{n}^{\circ} 26$, 2018, y hace ya algún tiempo Santaolalla, F., «Problemas jurídico-políticos del voto bloqueado», REP, $\mathrm{n}^{\circ}$ 53, 1986, pp. 29-43. Entre los que apuestan por listas abiertas Almagro Castro, D., «La apertura de las listas electorales: ¿un primer paso hacia la superación de la crisis de representatividad en la democracia española?», REDC, $\mathrm{n}^{\circ} 112,2018$, pp. 115-143. En sentido contrario, por entender que un desbloqueo de las listas —qué decir de su apertura— afectaría gravemente al sistema de partidos, ZovatTo, D. y Aguilar, L., «Algunas consideraciones sobre el uso del voto preferente y sus efectos en los sistemas democráticos», $R D E$, $\mathrm{n}^{\circ} 15,2013$, pp. 222-223. Más específicamente, rechazando utilizar alguna posibilidad en este sentido en el ámbito local Bertrana Horta, X. y Magre Ferrán, J., « ¿Hacia una reforma del sistema electoral municipal en España? Explorando la apertura de listas», en AA.VV., Buen gobierno, transparencia e integridad institucional en el gobierno local, M. Villoria Mendieta (Dir.) - X. ForCadell (coord.), Tecnos, Madrid, 2016, pp. 429-430 y $432-433$. 
limita el efecto de la cercanía), y se subraya la relevancia de los territorios que se constituyen en circunscripciones (la circunscripción pequeña facilita la representación territorial). Sensu contrario, si el tamaño es grande, hay más proporcionalidad, menor relación entre votantes y elegidos y mayor correspondencia con la idea de representación nacional. La mayor ventaja de la opción por una circunscripción nacional única, máxime cuando no va acompañada de barrera o umbral electoral alguno como sucede en el caso español, consiste en que produce unos resultados muy proporcionales. Y, tras posicionarse estableciendo la prioridad en la búsqueda de la mayor proporcionalidad posible, concluyó que la mejor fórmula era la del sistema todavía hoy vigente de la LOREG consistente en una circunscripción electoral única sin barrera electoral. Rechazó, asimismo, la opción de establecer circunscripciones de dos niveles — nacional y autonómico- Reconoció que así resultaría posible conciliar proporcionalidad del sistema electoral y proximidad entre electores y elegidos. Pero la mayor complejidad para articular dicho sistema y las dudas sobre que el mismo pudiera conducir a resultados distintos de los ofrecidos por el sistema de circunscripción electoral única, le llevaron a inclinarse por este último ${ }^{19}$.

\section{LA ELECCIÓN DIRECTA DE ALCALDES ${ }^{20}$}

En España, existen distintas formas de elección del alcalde en función del tamaño del municipio: el sistema de concejo abierto (los electores eligen directamente al alcalde por sistema mayoritario, art. 179.2 LOREG); el sistema electoral aplicable en los municipios con población comprendida entre 100 y 250 habitantes (se aplica un sistema mayoritario plurinominal de listas abiertas —art. 184-y la elección del alcalde se produce en los términos previstos en el art. 196 LOREG: pueden ser candidatos a alcalde todos los concejales — no necesariamente los que encabecen una lista- y resulta elegido el que obtiene la mayoría absoluta de los votos de los concejales; si ninguno obtuviese dicha mayoría es proclamado alcalde el concejal que hubiera obtenido más votos populares

19 Sensu contrario, la opción de introducir circunscripciones de ámbito autonómico con diecisiete autonomías y dos ciudades autónomas llevaría a que muchas de ellas solo pudieran elegir uno o dos diputados, lo que convertiría al sistema electoral en mayoritario debido al bajo número de representantes a repartir. Otra opción, consistente en reagrupar varias Comunidades Autónomas a efectos de configurar circunscripciones extensas, reforzaría la proporcionalidad pero el referente territorial, que reclaman los partidos de ámbito autonómico, se diluiría. Cualquier reforma en este sentido puede implicar un grado de complejidad elevado y potenciar una posible modificación de los resultados actuales que no permite que sea aconsejable su adopción; Gavara de CARA, J.C., «La reforma de la LOREG: expectativas y alcance», La reforma de la Ley Orgánica del Régimen Electoral..., cit., pp. 92-93.

20 Un comentario sobre este punto concreto del Informe del Consejo de Estado en CORCHERO PÉREZ, Miguel y SÁNCHEZ-PÉrez, L., «La elección directa de los alcaldes según el Informe del Consejo de Estado sobre la reforma electoral», Consultor de los ayuntamientos y de los juzgados: Revista técnica especializada en administración local y justicia municipal, $\mathrm{n}^{\circ}$ 19, 2014. 
en las elecciones de concejales); el sistema electoral aplicable en los municipios denominados de régimen común de más de 250 habitantes, la mayoría, que no se organizan en sistema de concejo abierto (la elección de los concejales se produce de forma muy similar a la diseñada para las elecciones al Congreso y la elección del alcalde es indirecta en los términos establecidos en el art. 196 LOREG: pueden ser candidatos todos los concejales que encabecen una lista y resultará alcalde aquel que consiga el apoyo de la mayoría absoluta de los concejales o, en su defecto, será proclamado el concejal que encabece la lista que haya obtenido mayor número de votos populares en el municipio. El empate se resolverá por sorteo); y el régimen electoral aplicable a entidades de ámbito inferior al municipio (art. 199 LOREG).

También existen distintos modelos de gobierno municipal, aunque se ha producido una evolución desde un sistema presidencialista a un sistema parlamentario. Dicha transformación se verifica en el caso de los municipios de régimen común pero, fundamentalmente, en relación con los municipios de gran población ${ }^{21}$ a raíz de la aprobación de la Ley 57/2003, de 16 de diciembre, de medidas para la modernización del gobierno local. En estos municipios, el giro hacia el gobierno parlamentario resulta clarísimo: se delimitan con precisión las funciones de control del Pleno al tiempo que se refuerzan las competencias de dirección encomendadas a un gobierno fuerte, compuesto por el alcalde y la Junta de gobierno local. El alcalde ocupa una posición institucional representativa y establece las directrices generales de la política municipal, mientras que las funciones de gobierno strictu sensu se encomiendan a un órgano gubernativo fuerte como es la Junta de gobierno local que nombra el Alcalde.

Como sabemos, el modelo de gobierno municipal y el sistema de elección del alcalde son asuntos intrínsecamente vinculados. Y, desde esta premisa, es desde donde el Consejo de Estado partió al analizar las propuestas de modificación del sistema electoral local consistentes en introducir la elección directa del alcalde.

La elección directa del alcalde, frente a la elección indirecta por los concejales, que lógicamente potenciaría la figura del alcalde, posible desde un punto de vista constitucional en atención a lo dispuesto en el art. $140 \mathrm{CE}$, se ha justificado por la conveniencia de reforzar su legitimidad democrática y representatividad, de garantizar una mayor gobernabilidad de la corporación municipal (se habla de la difícil formación de mayorías en el pleno municipal que suponen un freno a la gobernabilidad) y de evitar fenómenos como el transfuguismo político en dicho ámbito. Ahora bien, su introducción implicaría incorporar elementos propios de

21 Son municipios de gran población aquellos cuya población supere los 250.000 habitantes; los municipios capitales de provincia cuya población sea superior a 175.000 habitantes; los que sean capitales de provincia, capitales autonómicas o sedes de las instituciones autonómicas; y los municipios cuya población supere los 75.000 habitantes, que presenten circunstancias económicas, sociales, históricas o culturales especiales. En los dos últimos casos se exige, además, que así lo decidan las asambleas autonómicas correspondientes a iniciativa de los respectivos Ayuntamientos. 
un sistema mayoritario que afectarían considerablemente al sistema de gobierno municipal de los municipios de régimen común y, muy especialmente, de los municipios de gran población. Y, en la medida en que todos nuestros intentos de mejora al respecto habían ido en la línea de reforzar su proporcionalidad en dichos municipios, y en tanto en cuanto el Consejo mostró implícitamente su preferencia por el sistema de gobierno parlamentario en el análisis de este asunto, se manifestó contrario a un cambio en este sentido ${ }^{22}$.

\section{CORRECCIÓN DE DEFECTOS DE LAS NORMAS QUE REGULAN LA CONFECCIÓN DEL CENSO ELECTORAL Y LAS CAMPAÑAS ELECTORALES; UTILIZACIÓN DE NUEVAS TECNOLOGÍAS}

Finalmente, el Informe del Consejo de Estado analizó algunas cuestiones puntuales y de carácter fundamentalmente técnico que merecían algún tipo de reforma con el objeto de mejorar nuestra regulación electoral.

Sobre la corrección del fraude en la inscripción del censo electoral, que no consideró un defecto estructural de nuestros procesos electorales, realizó algunas propuestas para mejorar la fiabilidad de su composición y perfeccionar los mecanismos previstos para responder ante posibles desviaciones (reclamaciones sobre datos censales fuera de periodo electoral, papel de la OCE, rectificación del censo en periodo electoral y proceso contencioso electoral). Sobre su confección, se adhirió a aquellas propuestas que venían sugiriendo un reforzamiento de las facultades de supervisión del INE. También consideró necesario prever una delimitación homogénea de los criterios de residencia habitual, y de su efectiva acreditación, que están en la base de las altas y bajas padronales y, en consecuencia, de una correcta formación del censo electoral. Sobre el control y rectificación del censo fuera de periodo electoral, rechazó las propuestas que abogaban por introducir el

22 Aunque, para solventar dicho problema, se ha dicho que, si se hubiera optado por la vía de la elección directa, se podría haber pensado en articular un sistema de elección directa a doble vuelta que permitiera el reagrupamiento de las fuerzas políticas a favor de un alcalde de tal forma que este pudiera iniciar su mandato con una mayoría sólida, obviándose algunas de las dificultades señaladas por el Consejo; GAVARA DE CARA, J.C., «La reforma de la LOREG: expectativas y alcance», La reforma de la Ley Orgánica del Régimen Electoral..., cit., pp. 91-92. En la doctrina, a favor de la modificación para permitir la elección directa de los alcaldes Ridao i Martín, J. y García i Martínez, A., «La elección directa del alcalde por los vecinos. Criterios para un régimen presidencialista en los gobiernos municipales», Revista de estudios de la Administración Local y Autonómica: nueva época, $\mathrm{n}^{\circ} 3$, 2015, pp. 77-93; Arnaldo Alcubilla, E., «Encuesta sobre el régimen electoral general», $T R C, \mathrm{n}^{\circ} 22$, pp. 49-50. En sentido desfavorable a la elección directa del alcalde JARAMILlO FERNÁNDEZ, M., «La polémica sobre la elección directa de los alcaldes», El Consultor de los Ayuntamientos, $\mathrm{n}^{\circ} 3$, 2015; SÁNCHEZ SAEZ, Antonio José, «El principio democrático en la Administración Local: la elección directa del alcalde y las potestades de autoorganización y sancionadora», REALA, n 302, 2011, p. 187; GARCÍA GARCíA, M.J., «La elección directa del Alcalde en el régimen local: justificación, alcance y repercusiones», REDC, $\mathrm{n}^{\circ} 91,2011$, pp. 251-254. 
sistema establecido por la Resolución de la OCE de 14 de febrero de 2006 en la regulación de la LOREG, pues supondría introducir excesivo detalle en la Ley Orgánica. También rechazó incluir en la LOREG una especie de acción popular en defensa de la correcta constitución del censo fuera del periodo electoral por entender que una ampliación de la legitimación en tal sentido probablemente contravendría la confidencialidad de los datos censales. No puso sin embargo objeción a la posibilidad de ampliar en una medida menor, fuera del periodo electoral, la legitimación en el procedimiento de control de la regularidad censal, y consiguiente petición de rectificaciones (hasta ese momento, la legislación solo preveía la posibilidad de que las personas directamente afectadas pudieran reclamar y actuar individualmente en defensa de su propia inscripción en el padrón). Con todo, señaló que dicha ampliación debía sujetarse a algún criterio objetivo de delimitación de interés legítimo en la materia —en realidad se mostró generoso ya que consideró que la base para esta legitimación podría situarse en un interés abstracto y general en la correcta composición del censo electoral-y que, además, debería superar un entendimiento estricto del acceso a los datos censales. En cualquier caso, en opinión del Consejo, los esfuerzos de una reforma atinente a la revisión de errores censales debían centrarse en el momento de la fase electoral con el objeto de corregir las limitaciones del recurso contencioso-electoral en este ámbito (art. 109 y ss. LOREG). Recordemos que la corrección de errores censales no era objeto de este recurso. La corrección de errores censales fuera de periodo electoral se articulaba a través de reclamaciones ante la OCE y frente a ella cabía interponer recurso preferente y sumario en vía contencioso-administrativa (artículo 38.5 LOREG - tras la reforma del año 2011 este apartado 5 pasó a ser el apartado 4 pero sin modificación de contenido-). La revisión de datos censales en periodo electoral se articulaba a través del específico recurso de urgencia previsto ante los Juzgados civiles de primera instancia (art. 40.1 LOREG). Contra ambas resoluciones cabía interponer recurso de amparo electoral ante el Tribunal Constitucional, no obstante lo cual, el ámbito de este recurso se había ceñido al proceso electoral strictu sensu y del mismo habían quedado fuera las cuestiones censales. En concreto, y tras el análisis de algunas posibilidades que descartó por los inconvenientes que planteaban, el Consejo se inclinó por la introducción de un nuevo recurso en la materia, esto es, un recurso contencioso censal específico para corregir las anomalías en el censo electoral durante el periodo electoral.

Pasando a otra cuestión, se mostró favorable a suprimir la prohibición contenida en la LOREG sobre la publicación y difusión o reproducción de sondeos electorales por cualquier medio de comunicación durante los cinco días anteriores al de la votación (prohibición solo referida a encuestas sobre intención de voto y no a las encuestas sobre voto emitido, que se realizan a pie de urna el día de la elección). Consideró que las razones aportadas para justificar dicha prohibición, o bien eran inconsistentes (evitar el condicionamiento del voto, garantizar su racionalidad y fomentar la participación, evitar la distracción de los electores), o bien 
podían alcanzarse de un modo más efectivo a través de otras medidas (como cuando se trataba de garantizar la objetividad de las encuestas electorales). A su juicio, este último argumento a favor de la prohibición, consistente en asegurar la efectividad de las normas que garantizaban la objetividad de las encuestas por la JEC antes de que se produjera la votación, era el más consistente; no obstante concluyó que la función de control que se encomendaba a la JEC presentaba limitaciones (su control no se extendía a la calidad de las encuestas sino exclusivamente a aspectos de carácter técnico y era frecuente que la publicación de las rectificaciones apenas tuviera repercusión entre los ciudadanos; y era muy complicado, teniendo en cuenta los plazos establecidos en el art. 69.4 y 7 LOREG, que las rectificaciones pudieran llegar a publicarse antes de la votación). Según el Consejo, existían otros mecanismos, más eficaces, para cumplir con el objeto de garantizar su objetividad y se refirió, en concreto, al régimen de infracciones y sanciones contemplados en la LOREG para combatir las conductas de quienes infringieran sus disposiciones en este punto. A todo ello añadió que la citada prohibición resultaba ineficaz, inoperativa, en el marco de la sociedad de la información y de las nuevas tecnologías (mencionó que los medios de comunicación internacionales no quedaban sometidos a dicha prohibición y la dificultad para realizar un control efectivo del uso de Internet al respecto).

Asimismo, el Consejo de Estado vertió algunas recomendaciones para mejorar la campaña institucional y la campaña electoral.

En relación con la primera propuso, en línea con las sugerencias de la JEC, ampliar el ámbito subjetivo del art. 50.1 LOREG para permitir que también los poderes públicos locales, no solo el Gobierno, pudiesen difundir campaña electoral institucional (recordemos que este precepto permitía realizar este tipo de campañas a los poderes públicos que en virtud de su competencia legal hubieran convocado un proceso electoral y que el art. 185 LOREG establece que «El Real Decreto de convocatoria es acordado en Consejo de Ministros a propuesta de los Ministerios del Interior y de Administración Territorial»). También sugirió que la regulación sobre la publicidad relativa a logros de gestión se recogiera en la LOREG con carácter básico (se contenían criterios diferentes sobre el asunto en la LOREG y en la Ley 29/2005, de 20 de diciembre, de Publicidad y Comunicación Institucional pero la reagrupación de la materia en una sola norma, la LOREG, no revestiría complejidad a propósito de la publicidad de los logros de gestión, ya que entonces ya era norma básica en el artículo 4 de la Ley 29/2005). Asimismo, advirtió de los riesgos que podía conllevar la extensión del objeto de la campaña institucional de tal forma que con la misma también se pudiera fomentar la participación ciudadana, en la medida en que dicho objetivo podía instrumentalizarse si con ello se intentaba orientar el voto.

En relación con la segunda, y tras descartar que la subvención por envío de sobres y papeletas electorales resultara atentatoria del principio de igualdad por otorgarse solo a los grupos que hubieran obtenido representación política 
suficiente para formar grupo parlamentario ${ }^{23}$, sí que, sin embargo, creyó conveniente reconsiderar la exigencia de formar grupo parlamentario —art. 175.3 de la LOREG - para poder disfrutar de dicha subvención denunciando la práctica de la formación artificiosa y efímera de grupos parlamentarios con el único objeto de percibir esta subvención. Planteó, para evitar este fraude, un sistema de adelantos de gastos electorales subvencionables (art. 133.4 LOREG) que permitiese evitar dichos efectos. Finalmente, y con relación a la propuesta de computar dicha subvención dentro del límite máximo de gastos electorales, señaló que dicho objetivo precisaría la reforma del art. 175 LOREG.

Para terminar, el Consejo de Estado analizó detenidamente las ventajas y riesgos inherentes a las propuestas de implantación del voto electrónico, aunque la impresión general que desprende la lectura de su Informe es la de su enorme prevención con respecto a dicha posibilidad por considerar sumamente complejo garantizar con él, especialmente si se articulaba a través de Internet, la limpieza del proceso y la objetividad de los resultados obtenidos, y por las dificultades que podía plantear de cara a garantizar elementos fundamentales del sufragio como su naturaleza personal o secreta. Además, el Consejo valoró el sistema de votación y escrutinio en España de manera positiva y de ello dedujo que su sustitución por el voto electrónico no parecía absolutamente necesaria ${ }^{24}$.

\section{EL IMPACTO DEL INFORME DEL CONSEJO DE ESTADO EN EL RÉGIMEN ELECTORAL GENERAL ESPAÑOL}

La LO 2/2011, de 28 de enero, por la que se modifica la LO 5/1985, de 19 de junio, del Régimen Electoral General, constituye la reforma más integral del sistema electoral español en comparación con otras modificaciones efectuadas de la LOREG desde que viera la luz el Informe del Consejo de Estado. El hecho de que los resultados conseguidos con su aprobación resultaran limitados si se toman en cuenta las previsiones iniciales de modificación, habida cuenta de la disparidad de intereses por parte de los actores políticos protagonistas del momento, no impide valorar positivamente el esfuerzo realizado en aquellos ámbitos en los que se pudieron alcanzar consensos, aun a pesar de que incluso, en dichos ámbitos, hayan sido o sean precisas nuevas reformas.

23 En todo caso, en la doctrina se ha discutido de manera bastante razonable sobre la conveniencia de mantener las ayudas electorales para los contendientes en el proceso electoral con el objeto de confeccionar sobres y papeletas electorales; GONZÁLEZ-Juliana MuÑOZ, Á., «Las subvenciones electorales a los partidos políticos en España», Revista Jurídica de Castilla-León, nº 36, 2015, pp. 25-26.

24 La máxima cautela se observa igualmente en Presno Linera, M.Á., «Premisas para la introducción del voto electrónico en la legislación electoral española», REP, $\mathrm{n}^{\circ} 173$, pp. 277-304 (en particular en las pp. 299, 302 y 303). 
El impacto de las sugerencias formuladas en el Informe del Consejo de Estado de 2009 en la reforma de 2011 es visible en alguna de las modificaciones introducidas a través de dicha norma, aunque nos parece un impacto de orden menor, ya que no se alcanzó ningún tipo de acuerdo en torno a algunos de los cambios de calado más sustancial que planteó el órgano consultivo en su Informe: la reforma de las elecciones al Congreso en la línea de mejorar la proporcionalidad del sistema, y la maximización de las posibilidades de voto de las personas de origen inmigrante en las elecciones locales, dos cuestiones especialmente sensibles en las que se pone de manifiesto la resistencia de las fuerzas políticas, que no doctrinal, al cambio ${ }^{25}$.

Como sabemos, la regulación de las elecciones al Congreso no ha cambiado en sus aspectos sustanciales desde que se produjera su regulación original por la LOREG a pesar de las sugerencias en este sentido de la doctrina y del Consejo de Estado. En el momento en el que el órgano consultivo elaboró su Informe preocupaba, además de la posibilidad de conseguir unas elecciones al Congreso más proporcionales en términos generales $\mathrm{y}$, por consiguiente, más representativas del pluralismo existente en el cuerpo electoral, la imposibilidad que tenían los partidos minoritarios de ámbito nacional con base electoral dispersa de conseguir una proporción de escaños adecuada al número de sufragios obtenidos, y, en menor medida (aunque también), la presencia de unos partidos nacionalistas en el Congreso que podían condicionar la política nacional sometiéndola a los exclusivos intereses particulares de determinados territorios. En la actualidad, el contexto difiere al del momento en el que se publicó el Informe. Con una Cámara más fragmentada como consecuencia de una alteración en el sistema de partidos y, sobre todo, en las preferencias electorales, preocupa fundamentalmente la existencia de Gobiernos de la nación prisioneros de determinadas exigencias contradictorias y/o insolidarias con el interés general (máxime si tenemos en cuenta que las fuerzas políticas no parecen entender que la cuestión territorial se ha convertido en una auténtica cuestión de Estado que exigiría cesiones por parte de todos los que tienen voluntad y capacidad de frenar el injustificado fenómeno independentista). La objeción que ponía el Consejo sobre la imposibilidad de computar al umbral electoral a nivel nacional por resultar inconstitucional no acaba de convencer ya que los escaños se seguirían repartiendo en función del número de votos obtenidos en la provincia. Un umbral electoral del $3 \%$ a nivel nacional no solo corregiría la

25 Con relación a la reforma del sistema electoral del Congreso ya se señaló lo improbable de la misma, a pesar de valorar positivamente el esfuerzo realizado por el Consejo de Estado, por parte de GARROTE DE MArcos, M., «La improbable reforma del sistema electoral del Congreso de los Diputados. Comentario el Informe del Consejo de Estado sobre reforma del sistema electoral», InDret. Revista para el Análisis del Derecho, $\mathrm{n}^{\circ} 4,2009$, p. 31. Por otra parte, señalando que la Subcomisión creada en el año 2010 para el estudio de la reforma del régimen electoral general había dejado invariados elementos medulares del mismo y que se había limitado a sugerir reformas de calado menor de orden procedimental, SANTOLAYA MACHETTI, P., «Estudio introductorio al Informe de la Subcomisión creada en el seno de la Comisión Constitucional sobre las posibles modificaciones del Régimen Electoral General, de 28 de junio de 2010», CDP, n 36, 2009, pp. $223-224$. 
desproporción de la atribución de escaños a fuerzas minoritarias de ámbito nacional con base electoral dispersa, sino que también limitaría la llegada de partidos con pretensiones exclusivamente territoriales al Congreso (suya sede natural debería ser el Senado —otra cosa sería cómo convertirlo en una auténtica cámara de representación territorial-) y reduciría el peso de los partidos nacionalistas y/o independentistas para convertirse en la llave de la gobernabilidad de España.

En relación con voto de la persona de origen inmigrante se continúa desconociendo el cambio sustancial que se ha producido de nuestra realidad social, con la llegada de un numeroso grupo de personas de origen inmigrante que se instala en las ciudades españolas con voluntad de arraigo y de desarrollar un proyecto vital y con respecto a las cuales deberíamos hacer todos los esfuerzos precisos para garantizar su integración y adecuada representación. Sin embargo, la LO 2/2011, de 28 de enero, no introdujo modificaciones sobre esta cuestión y, por consiguiente, en la actualidad, la posibilidad de atribuir los derechos de sufragio activo y pasivo en las elecciones locales a las personas de origen inmigrante en nuestro país sigue dependiendo, fundamentalmente, de la necesaria conclusión de un acuerdo internacional con otro Estado y del alcance de la interpretación de la exigencia de reciprocidad. El tema, pues, se reconduce todavía hoy a través del derecho internacional. Además, en general, se ha utilizado un entendimiento restrictivo de la exigencia de reciprocidad (los tratados suelen reflejar condiciones muy similares para el ejercicio del derecho de voto entre las dos Partes). Solo contemplan el sufragio activo - se establece como requisito general un periodo previo de residencia legal en España de al menos cinco años ${ }^{26}$ - pero no el pasivo. Por consiguiente, y a pesar de que pudiera hacerse una valoración moderadamente positiva del esfuerzo de conclusión de tratados internacionales que se produjo sobre esta materia entre los años 2009 y 2011, tras los primeros antecedentes de reconocimiento convencional en los años ochenta y noventa del siglo anterior, lo cierto es que dichos esfuerzos, por una parte, han quedado muy lejos de lo sugerido por la doctrina y por el Consejo de Estado, y, por otra, no han conseguido incentivar la participación en las elecciones locales de sus destinatarios.

26 En algunos casos se puede dar la paradoja de que se consiga el acceso al voto a través de la nacionalidad antes que a través de la previsión en el tratado (según el CCi, puede ser más rápido obtener la nacionalidad española — para personas procedentes de determinados países solo se requieren dos años- que beneficiarse de estos tratados). Y es evidente que la adquisición de la nacionalidad es otra vía por la que los residentes de origen inmigrante en nuestro país pueden adquirir derechos políticos. Pero coincidimos los que han señalado que la adquisición de la nacionalidad no debe ser la única vía para el ejercicio de los derechos políticos por parte de los extranjeros, máxime cuando hay numerosos casos en los que la adquisición de la nacionalidad española llevaría aparejada la pérdida de la nacionalidad de origen, lo que puede suponer un precio muy alto para el interesado, en especial para el caso de los inmigrantes de primera generación; PRESNO Linera, M.Á., La reforma del derecho de voto en ..., cit. El periodo de residencia previa puede discutirse, pero me parece razonable exigirlo como muestra de estabilidad y arraigo en el país. En sentido contrario, afirmando que no debe exigirse plazo de residencia legal mínimo, bastando con ser titular del correspondiente permiso de residencia, ARCE Jiménez, C., «Análisis de los tratados internacionales para el reconocimiento del derecho de sufragio local a personas extranjeras residentes en España que no ostentan la ciudadanía...», cit. 
Tampoco encontraron acomodo en la LO 2/2011, de 28 de enero, otras sugerencias como la conveniencia de regular expresamente los medios específicos de la campaña electoral en el exterior, la posibilidad de introducir alguna forma de voto preferencial, la supresión de la prohibición de publicar y difundir o reproducir sondeos electorales por cualquier medio de comunicación durante los cinco días anteriores al de la votación, la ampliación de los sujetos legitimados para realizar campaña institucional, o las sugerencias que realizó con relación a la subvención de gastos electorales (aunque sí se introdujeron otro tipo de modificaciones por parte del legislador orgánico del año 2011 en relación con la subvención de gastos electorales y utilización de los medios de comunicación durante la campaña electoral ${ }^{27}$ ).

Entre las propuestas del Consejo de Estado que encontraron reflejo en la LO 2/2011, de 28 de enero, habría que destacar la supresión del derecho de voto en elecciones locales por parte de los españoles residentes en el extranjero (en la nueva redacción dada a los arts. 2.3, 75 y 190 LOREG). Pero tampoco se siguió, exactamente, la recomendación del Consejo de Estado, el cual, consciente de la dificultad de suprimir sin más el derecho de sufragio activo de estos españoles en elecciones locales, se había inclinado en su Informe por la adopción de soluciones alternativas a la mera denegación del voto exterior en el ámbito local desde la adquisición de la residencia en el país al que se había emigrado. La controversia a que dio lugar dicha reforma demostró que dicha dificultad era real. La modificación fue objeto de un recurso de inconstitucional que el TC resolvió en su sentencia 153/2014, de 25 de septiembre. El Tribunal desestimó el recurso por entender que la reforma no vulneraba derecho fundamental alguno ${ }^{28}$.

27 Sobre estos asuntos véase, entre otros, García Mahamut, R. y Rallo Lombarte, A., «Neutralidad y pluralismo de los medios de comunicación en las campañas electorales: la reforma de la LOREG de 2011», REDC, ñ 98, mayo-agosto 2013, pp. 201-240; PAJARES MonTolío, E., «La financiación de los partidos políticos», Eunomía. Revista en Cultura de la Legalidad, no 11, octubre 2016-marzo 2017, pp. 182-185; GonZÁlEZ-Juliana MuÑoz, Á., «Las subvenciones electorales a los partidos políticos en España», RJCL, ${ }^{\circ}$ 36, 2015, pp. 1-34.

28 El Gobierno de Canarias interpuso el recurso de inconstitucionalidad núm. 2398-2011, que fue admitido por providencia por el TC, en relación con el artículo único, apartados uno, veintiocho y cincuenta y cinco de la LO 2/2011, que eran los preceptos que se referían o tenían que ver con dicha supresión. La sentencia -ECLI:ES:TC:2014:153 - se encuentra publicada en el BOE n 261 , de 28 de octubre de 2014. Fundamentalmente, sostuvo que la diferenciación entre españoles residentes y no residentes en España en cuanto al ejercicio del voto en elecciones locales no contraviene el principio de igualdad en relación a su participación en los asuntos públicos a través del sufragio (según el Tribunal, estaríamos ante dos supuestos de hecho sustancialmente diferentes y, por consiguiente, la diferencia de trato contaría con una justificación objetiva y razonable que impediría calificar la reforma de arbitraria). Además, el Tribunal resaltaba, a mayor abundamiento, que las tendencias contemporáneas buscan disociar la nacionalidad del derecho de sufragio en las elecciones locales y vincular dicho derecho a la residencia y la vecindad, lo que resultaría mucho más adecuado atendiendo al actual contexto social migratorio (recurso al Derecho comparado); y subraya también las disfuncionalidades y distorsiones que antes de la reforma de 2011 había provocado el voto de españoles residentes en el extranjero (argumento pragmático). Tampoco vulneraría la reforma el artículo 68.5 CE, que se refiere exclusivamente a elecciones al Congreso, sino que, más bien, dicha reforma resulta más acorde con el contenido del artículo 140 del mismo texto, que habla de «vecinos». 
También encontraron reflejo algunas propuestas del Consejo de Estado de índole más técnica, como la de ampliar la legitimación para pedir la rectificación del Censo Electoral fuera del periodo electoral (el nuevo art. 38.2 LOREG, tras la reforma del año 2011, atribuye legitimación a los representantes de las candidaturas o representantes de los partidos, federaciones y coaliciones para impugnar el censo de las circunscripciones que hubieren registrado un incremento significativo y no justificado de residentes que hubiera dado lugar a la comunicación referida en el art. 30.c LOREG). O la previsión de un recurso contencioso-electoral específico durante el proceso electoral (el nuevo art. 40 LOREG) ${ }^{29}$. O la inclusión de la regulación de la campaña institucional y lo relativo a la publicidad de logros de gestión en la LOREG con carácter básico (art. 50.1, 2 y 3 de la LOREG).

Sin embargo, a proposito de otros asuntos, el legislador orgánico de 2011, sencillamente, decidió algo diferente a lo sugerido en el Informe del Consejo. Así sucedió en relación con la recuperación del voto rogado para las elecciones de los españoles residentes en el extranjero (naturalmente, con exclusión de las locales en las que a partir de ese mismo año no iban a poder participar), o en relación con la introducción del voto en urna en el exterior que, como vimos, había desaconsejado el órgano consultivo debido a las serias dificultades técnicas para su correcta implantación.

Recordemos que el Consejo de Estado había realizado una valoración positiva de la supresión del voto rogado en este ámbito en el año 1995. Pero el legislador orgánico del año 2011 optó por recuperarlo [tras la reforma, el elector debe solicitar su ejercicio - la reforma consagra el voto rogado en todo tipo de comicios en los que el español en el exterior puede y pretende votar- pudiendo optar entre su envío postal (voto por correspondencia) o su depósito consular (voto en urna)], generando la consiguiente polémica doctrinal que lo discute con contundencia por constituir un obstáculo que desincentiva la participación ciudadana desde el exterior habida cuenta de la carga burocrática que conlleva (aunque probablemente, esta reforma se incluyó con la intención de distinguir entre aquellos españoles en el exterior que habían perdido el interés por la cosa pública española y aquellos otros que seguían conservando su interés y que, por consiguiente, iban a realizar los trámites pertinentes — cualquier tipo de trámite siempre es costoso— para poder emitir su voto) ${ }^{30}$. Además, la LO 2/2011, de 28

29 Valorando positivamente esta reforma, debida desde hacía tiempo, que paga el coste en términos de proximidad para obtener a cambio una decisión jurisdiccional especializada, CHUECA RodríGuez, Ricardo, «Cambios, reformas y adaptaciones», La reforma de la Ley Orgánica del Régimen Electoral..., cit., P. 35. En todo caso, las modificaciones introducidas por la LO 2/2011 con relación al censo electoral, con el objeto de evitar desfases y fraudes, fueron más que las mencionadas en este texto. Un repaso de las mismas en GAVARA DE CARA, Juan Carlos, «La reforma de la LOREG: expectativas y alcance», La reforma de la Ley Orgánica del Régimen Electoral..., cit., pp. 97-101.

30 Antes de la reforma legal, el voto rogado solo operaba en las elecciones municipales. Tras la reforma, se ha impuesto el voto rogado en todo tipo de comicios. Muy crítico al respecto, manteniendo la posición favorable a la supresión del voto rogado para incentivar la participación de estos electores, MATEO CRESPO, J.L., «La implantación del «voto rogado» en España: el perjudicial límite a la participación electoral de los 
de enero, introdujo el voto en urna en el consulado, basado en un depósito consular del mismo para su posterior traslado a la Junta Electoral correspondiente, si bien manteniendo el voto por correspondencia para todos aquellos que no pudieran o quisieran desplazarse a votar en la dependencia habilitada al efecto. El impacto negativo de la recuperación del voto rogado para el ejercicio del derecho por parte de los españoles residentes en el exterior en términos de participación, así como las dificultades y defectos que se han producido en la aplicación del sistema del voto en urna, han generado la correspondiente discusión sobre posibles alternativas. Las instrucciones y acuerdos de la JEC, que han resultado clave para mitigar los problemas planteados por el voto de los residentes en el exterior, no han conseguido solucionarlos. Es más, la propia JEC elaboró un informe sobre la regulación del voto de los electores españoles que residen o se hallen en el extranjero, aprobado en sesión de 16 de noviembre de $2016^{31}$, en el que puso de manifiesto la existencia de graves dificultades técnicas para garantizar una correcta aplicación del voto en urna y elevó a las Cortes Generales y al Gobierno sus conclusiones a los efectos de que pudieran considerar la posibilidad de establecer el procedimiento de voto telemático vía Internet para los inscritos en el CERA (también para los electores residentes temporalmente ausentes) ${ }^{32}$. Precisamente, el Consejo de Estado, muy reacio en su Informe a sustituir el voto presencial en urna por el sistema de voto electrónico, indicó, sin embargo, que este podía ser un ámbito en el que el voto telemático debiera implementarse, naturalmente, extremando las garantías, especialmente si dicho voto se formulaba vía Internet.

Finalmente, el Consejo de Estado rechazó de plano la previsión de una circunscripción electoral especial para las elecciones de los extranjeros residentes en el extranjero, y, más allá, de cualquier modificación en el modelo existente (vimos cómo ninguna de las alternativas que valoró le resultaron convincentes). Lo mismo hizo con la posibilidad de modificar la circunscripción electoral nacional para las elecciones al Parlamento Europeo. O con la posibilidad de prever una elección directa de los alcaldes. O con la ampliación de la finalidad de la campaña institucional para permitir que, a su través, se incentivara la participación. Y se mostró

españoles residentes en el extranjero a punto de enmendarse», TRC, $\mathrm{n}^{\circ} 43,2019$, pp. 447-451. Solicita la contrarreforma consistente en la supresión del voto rogado en el exterior y propone restringir el voto rogado exclusivamente al voto por correspondencia; Ruiz GonZÁlez, J.G., «El voto exterior en España», Más Poder Local. En Portada, 2014. El autor también propone valorar la conveniencia de introducir algún sistema de voto electrónico apoyándose en lo que dijo el Consejo de Estado y señalando que este modelo permite superar la distancia, que es el principal obstáculo al que debe enfrentarse cualquier modelo previsto para los españoles ausentes.

31 Número de Acuerdo 261/2016. Número de Expediente 109/160.

32 En todo caso, este Informe de la JEC contempla también esta posibilidad con suma cautela debido a las dudas razonables que plantea, véase «Informe de la Junta Electoral Central de 16 de noviembre, sobre la regulación del voto de los electores españoles que residen o se hallen en el extranjero», Revista de las Cortes Generales, $\mathrm{n}^{\circ} 107,2019$, pp. 465-467. 
sumamente cauteloso con la posibilidad de introducir el sistema de voto electrónico. El legislador orgánico en el año 2011 tampoco recogió previsión alguna al respecto.

$$
* * *
$$

TiTLE: The Impact on the Spanish Law of the State Council Report related to the Proposal to Reform the General Electoral System

ABstract: In 2008, the Government answered to the Consejo de Estado about the possibilities of changes in our electoral system without modifying the Constitution. The result was the Report on the proposals to modify the electoral system of February 24, 2009. This work has got an unquestionable technical quality, which has made it a mandatory reference text for all those who analize the reform of the Spanish electoral system. It is also analyses the subject with laudable caution. It is worthwhile, after ten years since it was published, to resume its principal conclusions and verify its impact on the reform of our electoral system in 2011.

Resumen: en el año 2008, el Gobierno consultó al Consejo de Estado sobre las posibilidades de reforma del régimen electoral general sin necesidad de proceder a una reforma constitucional. El resultado fue el Informe sobre las propuestas de modificación del régimen electoral general de 24 de febrero de 2009. Este trabajo se caracteriza por dos rasgos: su indiscutible calidad técnica, que lo ba convertido en un texto de referencia obligada para todos aquellos que analizan en España la reforma del sistema electoral general, y una laudable cautela en el tratamiento del tema. Merece la pena, después de diez años desde que viera la luz, retomar el mismo a fin de comprobar cuál fue su verdadero impacto en la reforma del régimen electoral general del año 2011.

KeY words: General electoral system, Consejo de Estado, Report.

Palabras clave: Régimen electoral general, Consejo de Estado, Informe.

FeCHA DE RECEPCIÓN: 14.01.2020 FeCHA DE ACEPTACIÓN: 19.02.2020 
